\title{
El historiador ante los medios de comunicación digitales. Una relación nueva
}

\author{
Manuel Alberto DE RAMÓN CARRIÓN \\ Universidad Complutense de Madrid \\ manuelalberto.ramon@ccinf.ucm.es \\ Pedro Paniagua Santamaría \\ Universidad Complutense de Madrid \\ ppaniagua@ccinf.ucm.es \\ Josep M. SANMARTí RoseT \\ Universidad Carlos III de Madrid \\ josemaria.sanmarti@uc3m.es
}

Recibido: 12 de junio de 2015

Aceptado: 28 de octubre de 2015

\section{Resumen}

La manera de hacer periodismo y los propios medios de comunicación han cambiado no sólo sus técnicas y sus formas, sino también los contenidos. En concreto, la presión ejercida por las nuevas tecnologías y el surgimiento de una sociedad muy relacionada con los medios digitales están remodelando en constante debate el mundo de la información. Por ejemplo, frente a los complejos fenómenos derivados de la inmediatez se presenta un nuevo periodismo de investigación basado en la acumulación y análisis de grandes cantidades de datos, que aporta otras visiones de la actualidad para ahora y para la posteridad. De este modo, las tradicionales relaciones entre la Historia y el Periodismo experimentan unas variaciones sustanciales a tomar muy en cuenta en las investigaciones en marcha o futuras. Ya no se trata de unos medios archivados que sirven de fuentes, sino de una visión distinta de la información y de la sociedad que la recibe.

Palabras clave: Historia; medios de comunicación; periodismo de investigación; inmediatez; Twitter.

\section{Historian with regard to digital media. A new relationship}

\begin{abstract}
The way to do journalism and the media themselves have changed not only their techniques and forms, but also the content. In particular, the pressure exerted by new technologies and the emergence of a society closely related with digital media are reshaping the world of information in a constant debate. For example, opposite to the complex phenomena derived from the immediacy is presented a new investigative journalism based on the accumulation and analysis of large amounts of data, which provides other visions of the present for now and for posterity. Thus, the traditional relationship between history and journalism experience substantial variations to take into account in ongoing or future investigations. No longer is a matter of archived media serving as sources, but a different vision of the information and its receiver society.
\end{abstract}

Keywords: History; media; investigative journalism; immediacy; Twitter. 


\section{Referencia normalizada}

Ramón Carrión, M. A.; Paniagua Santamaría, P.; Sanmartí Roset, J. M. (2015). El historiador ante los medios de comunicación digitales. Una relación nueva. Historia y Comunicación Social. Vol 20, número 2, páginas 579-599.

Sumario: 1. Introducción. 2. La información constante. El sistema "película". 3. El Periodismo de Investigación, como vía alternativa a la rebaja del rigor. 4. La veracidad de las fuentes como principal valor periodístico. 5. Twitter como herramienta de divulgación y metodología del estudio. 5.1. Las cuentas de Twitter en el campo de la Historia. 6. Anexo estadístico. 7. Conclusiones. 8. Referencias bibliográficas.

\section{Introducción}

En octubre del 2000 los firmantes de este artículo presentaron otro en el que se analizaba los medios de comunicación no sólo como fuentes de la Historia, sino como indicadores de ella (Sanmartí, Paniagua, Ramón, 2002: 437-446). Al mismo tiempo, Matilde Eiroa exploraba las concomitancias y las distancias entre el Periodismo y la Historia del Tiempo Presente (HTP) y llegaba a la conclusión de que la digitalización

resulta de suma utilidad para la HTP y sus investigadores si diseccionan y analizan escrupulosamente los contenidos e imágenes de los media para reconstruir racionalmente la Historia de lo que nos rodea (2002: 385-398).

Desde entonces no ha pasado mucho tiempo, pero estas relaciones han variado en especial por la explosiva expansión de la digitalización en todos los campos y concretamente en el de la información (Eiroa, 2014: 253-264).

Partiendo del esfuerzo para aportar por un lado el máximo rigor en la elaboración de las informaciones y por otro rehuir en lo posible la inmediatez, se podría abogar por un uso de Internet más sosegado, más reflexivo, más profundo... más en consonancia, en definitiva, con lo que puede esperarse de una herramienta para la Historia. Todo ello avala la idea de que es posible un uso de los medios digitales riguroso y no apresurado, pese a que en un primer momento, hace casi ya dos décadas (momento en el que empezaron los primeros diarios en Internet), la rapidez fuera la virtud más destacada, y casi única de los nuevos medios. Ni la Historia, ni -obviamente- el Periodismo tienen nada contra la rapidez en sí misma, pero sí contra la superficialidad y la trivialización que esa rapidez lleva aparejada de manera casi inevitable cuando lo único que se pretende es el titular explosivo o el tuit visceral, y su traducción instantánea en lectores/seguidores.

El frenesí irreflexivo vino a su vez propiciado por la inevitabilidad proclamada de la muerte del papel. Como al parecer el papel agonizaba sin remedio, no había otra solución que adaptarse al mundo digital y esa adaptación -urgente en sí misma- se refería sobre todo a la urgencia en la transmisión de la información. Naturalmente, si el cambio de formato del periodismo tradicional al digital lo hubiera sido sólo de soporte, los nuevos medios no habrían supuesto ninguna alteración en el oficio de historiador. Por su propia naturaleza el historiador está acostumbrado a trabajar con 
todo tipo de materiales; es más, se podría añadir que en la dificultad del soporte se encuentra muchas veces el valor de la labor historiográfica. Sin embargo, lejos de suponer sólo un cambio de soporte, la adaptación a los medios de comunicación digitales, trajo un conflicto entre inmediatez y profundización. Quizá haya llegado el momento de plantearse que ambos conceptos pueden no ser incompatibles.

\section{La información constante. El sistema "película"}

Sin dejar de lado los medios en soporte papel, la multiplicación y el desarrollo de los digitales han promovido, junto con otros instrumentos de comunicación, la hiperinformación característica de nuestra sociedad, que en muchos casos ha derivado en la "infoxicación", o sobrecarga de información difícil de procesar. No es de extrañar que pensadores como el alemán Byung-Chul Han afirmen que esta inmensa masa informativa no sirve para aclarar las situaciones y que incluso las complica, impidiendo las jerarquías y los órdenes en las noticias (Han, 2013). El resultado, pues, es una trama casi inextricable de medios tradicionales y digitales aplicada a casi todos los ciudadanos y de la que hay que extraer trabajosamente la información objetiva y subjetivamente correcta. Juan Yunquera lo resume diciendo que

el hecho de ser "omnívoros digitales" conlleva el bombardeo de estímulos desde todos los canales de acceso a la información. Consumimos información a través de diarios, revistas, periódicos gratuitos, páginas web, blogs, publicaciones para tabletas y teléfonos móviles inteligentes, agregadores de noticias o a través de los flujos informativos que proporciona la Red (2014: 36).

Para el tema que nos concierne, se trata por un lado de una cantidad enorme de noticias y comentarios, y por el otro de su fluidez constante, sin interrupciones importantes hasta el punto de que no pocos acontecimientos son seguidos incluso al minuto. La información se transforma, por lo tanto, en una "película" sobre la actualidad. Buena prueba de ello es que las noticias aparecen habitualmente con la hora y el minuto de su publicación y de su última actualización. Se convierten así en una secuencia en variación constante, con una fuerte volatilidad, y de rápida lectura. Sucesos que a las nueve de la mañana encabezan un periódico digital, al cabo de una hora pueden haber sido relegados, sufrido modificaciones esenciales y hasta haber desaparecido. Es lo que Jean-François Fogel llama "la narración en tiempo real". O dicho en palabras de Josep $\mathrm{M}^{\mathrm{a}}$ Casasús,

en el Periódico Digital, la Periodicidad desaparece con el desarrollo de un nuevo concepto que defino con el término Continuidad. La Continuidad ya era un valor incorporado al Periodismo en Radio y en Televisión, pero no era posible aplicarlo hasta hoy al Periodismo Escrito... La Continuidad representa, pues, un cambio de primer orden en los recursos y procedimientos para la obtención, tratamiento escrito y difusión textual de las noticias (2005: 168-182).

Esta fragmentación de los relatos periodísticos dificulta la visión global, la perspectiva general de los acontecimientos, transformándose en "píldoras" dispersas de 
embrollada comprensión. En el mejor de los casos deben ser completados con resúmenes y reportajes que aporten dicha visión global.

No obstante, no siempre ocurre así. Por ejemplo, es muy probable que una entrevista no sea retocada en versiones posteriores, como sí sucede con las noticias. La abundancia de medios multiplica también los modelos. Por poner un caso, Jot Down Cultural Magazine

ha roto con la idea de que vivíamos en una cultura digital de "fast reading" y que era el único modelo posible. Sus entrevistas en profundidad así lo demuestran (Magallón, 2013).

Esta fluidez extrema debilita y muchas veces anula uno de los papeles básicos de la prensa tradicional, que es el de la "agenda setting", es decir establecer los temas de actualidad (del día casi siempre) sobre los que las audiencias deben formar su opinión, y llegado el caso tomar decisiones. Posiblemente ahora esta función se está trasladando a ciertas redes sociales con sus "trending topics" y similares, eso sí con una inestabilidad permanente.

Otra consecuencia importante es la disminución del papel de los medios como mediadores entre las fuentes y las audiencias (la "desintermediación"), compensada por un frenético y tumultuoso crecimiento de la interactuación con los lectores. Se trata del discutido fenómeno del "periodismo ciudadano" o del "wikiperiodismo", según la expresión de Juan Luis Cebrián (2011). La interacción medios-audiencias a través de numerosas fórmulas ha planteado, no obstante, grandes y graves problemas en lo que respecta a la identificación de elementos dispuestos a desatar falsos debates o crear problemas ("trolls"), o a la segmentación de los participantes.

La inmediatez pasa a ser así el valor fundamental de los medios digitales. Lo importante es difundir la noticia lo antes posible gracias a la velocidad de comunicación que permiten las tecnologías actuales, convirtiéndose en la primera premisa del Periodismo. La competencia se establece mucho más en la rapidez que en los contenidos, que ya se modificarán a medida que lleguen nuevos datos. Por eso, el chileno Guillermo Culell afirma sin ambages que "la tendencia futura pasa por flujos mucho más acelerados de información, más instantáneos" (Gutiérrez, 2011).

Los valores de los medios tradicionales basados en la contrastación y verificación de fuentes y datos ceden el paso a la prontitud y al cambio permanente sin depender de horarios o lugares. Es verdad que la prisa siempre ha sido un factor clave en los medios de comunicación, por lo que no resulta un elemento ajeno o incluso novedoso en las prácticas periodísticas de ahora y de siempre. Algunos medios audiovisuales, como la radio, conocen muy bien la ley de la inmediatez, aunque sin duda la digitalización está acelerando y ampliando este proceso, hasta el punto de que por ello mismo la información resultante está sujeta a enfoques y redacciones distintas. Dicho de otro modo, es otro tipo de información para una sociedad conformada sobre estos otros valores y estas tecnologías. 
Si se consideran estos medios como una fuente (para historiadores, para los propios medios o para otros sectores) se plantea el problema de tener que establecer el corte temporal apropiado. En qué hora y en qué minuto debe valorarse la información como dato útil y fiable.

El precio de esta ventaja es la posible falta de rigor en la elaboración de las noticias (Casero, 2014: 256-259). Falta de rigor para la que hay mucha más tolerancia en los medios digitales precisamente por su capacidad de rectificar a un coste mínimo. Estas técnicas periodísticas instaladas en la velocidad es lo que revaloriza en opinión de muchos los medios tradicionales, principalmente la prensa de papel, en una labor más sosegada, más reflexiva, menos dependiente de la inmediatez y que permite aplicar los cánones profesionales y deontológicos con mayor comodidad. Sin embargo, la posibilidad de enmendar lo publicado no exime a los medios digitales de aplicar al máximo los controles de rigor periodístico necesarios para garantizar una información veraz y de calidad, y es que como asegura Alfonso Armada, el prestigio de una publicación, sea digital o en papel, está basado en el rigor (2014).

\section{El Periodismo de Investigación como vía alternativa a la rebaja del rigor}

Aunque con antecedentes en los años 1920, el auge de los nuevos medios digitales ha impulsado y se ha beneficiado de la reactivación del Periodismo de Investigación (PI) vinculado con frecuencia a medios sin fin de lucro. Las exitosas experiencias del Texas Tribune, Voice of San Diego, Propublica, o Wall Street Journal animaron a muchos otros a reunir fondos para financiar investigaciones destinadas a un periodismo de calidad (Elola, 2010). Esta técnica propicia una mejor selección de los temas sin tener que depender de la actualidad inmediata, un proceso de búsqueda y contrastación de datos más largo y especializado, y una elaboración más cuidadosa del artículo final, habitualmente en género reportaje.

Para algunos el asunto de partida, además de novedoso, tiene que ser secreto en su totalidad o en sus partes esenciales con el fin de justificar la investigación. El secretismo suele ser un componente básico, ya que se trata de aflorar información oculta por distintas razones. Casi automáticamente se le asocia a la denuncia y a la lucha contra la corrupción o el abuso de poder en todas las áreas posibles. Por esta razón es considerado como la mejor vertiente de la función de guardián de la democracia ("watchdog") que se atribuye al Periodismo en general. La tendencia general a intensificar la transparencia en las administraciones mediante leyes específicas ha ayudado al PI, que ha visto ampliado su campo de acción y sus fuentes, así como a disminuir los peligros y las represalias de distinto orden.

$\mathrm{Su}$ gran problema es el coste en tiempo, dinero y recursos. La necesidad perentoria de tener que amortizar las inversiones fuerza en no pocas ocasiones resultados mal contrastados e incluso sin interés. En otras, el PI sirve de pantalla para asuntos 
vinculados al sensacionalismo que adquieren bajo este manto una apariencia más honorable.

Como fuente para los historiadores, el PI puede ser lógicamente de una gran ayuda, en la medida en que realiza una labor de desbroce antes de que el tema tratado sea sometido a los procedimientos propiamente históricos, como veremos más adelante.

Con todo, algunos periodistas, como $\mathrm{M}^{\mathrm{a}}$ Pilar Diezhandino o el propio Gabriel García Márquez, han defendido la idea de que todo periodismo, por definición, debe ser de investigación, puesto que éste tiene que buscar y procesar la información con las máximas garantías posibles (Díaz, 2003).

En la segunda mitad de los años 1970 el uso creciente de bases de datos informatizadas significó una revolución en su recopilación, almacenamiento y tratamiento. Por esto Lorena Romero afirma que

nos encontramos con un instrumento básico del que puede hacer uso cualquier individuo (un universitario, un economista, un docente, un político, un militar, y todas las categorías que se nos antoje añadir a esta enumeración), pero muy especialmente el periodista, pues este profesional tiene en ellas una fuente de saber de dimensiones espectaculares que supera con creces el conocimiento presencial que pueda tener de la realidad sensible que ha de suministrar, una vez elaborada, a sus receptores (2005: 485).

El posterior desarrollo de la Red ha incrementado el uso de esta herramienta hasta extremos insospechados hace pocos años y ha permitido el acceso de los medios a cantidades ingentes de datos. Se recorta enormemente así la técnica tradicional del muestreo o de lo representativo, por ejemplo en las encuestas, para emplear series mucho más extensas y complejas. Por ejemplo, el análisis de 800.000 tweets puede resultar más exacto que el de 3.000 muestras por teléfono. En segundo lugar, se puede prescindir de la exactitud de los datos sustituyéndola por tendencias más fiables. Y en tercer lugar se comprime la búsqueda de la causalidad, ya que

en un mundo de datos masivos ya no nos es necesaria, sino que podemos actuar a través de algo mucho más útil, como son las correlaciones. Se trata de medir las distintas variables relacionadas en un fenómeno y poner los datos en común. De ese modo, y a través de los mecanismos analíticos digitales, descubriremos qué es lo que pasa aunque no sepamos por qué. "Las correlaciones no nos dicen la causa de lo que ocurre, pero sí nos alertan de que algo pasa", aseguran los autores de Big data (Hernández, 2013).

Entre muchas otras las experiencias de Wikileaks o de la plataforma filtrala.org (2014) demuestran su potencialidad informativa y sus posibilidades. La práctica del llamado "data driven journalism" es "una de las conquistas de la democracia moderna, y lo va a ser cada vez más”, en opinión del brasileño Rosental. C. Alves (2010). 


\section{La veracidad de las fuentes como principal valor periodístico}

Para analizar la compatibilidad, o incluso complementariedad -ya veremos-, entre urgencia y rigor nada mejor que asomarnos a un medio digital de hoy en día y tomar un texto que tenga un claro calado histórico. Por supuesto que para apreciar esta condición no vale sólo la perspectiva temporal, pues entonces no tendría sentido hablar de Historia del Tiempo Presente. Hay otros parámetros como consecuencias, repercusión, influencia -muchos de ellos presentes entre los criterios básicos de selección y valoración de la información periodística- que también pueden ser indicadores de la trascendencia histórica de un acontecimiento. Por ejemplo, el 21 de enero de 2014 elpais.com publicaba un artículo cuyo titular decía: "Un informe acusa al régimen sirio de "torturas y asesinatos sistemáticos"”. Al epígrafe anterior le seguían dos subtítulos: " 11.000 presos han muerto en la cárcel, según un informe publicado por The Guardian y CNN" y "Tres fiscales internacionales han elaborado el documento con pruebas obtenidos por desertores". Errores de redacción al margen, nótese que la fuerza del titular no gravita sobre los horrores del régimen sirio, con ser estos graves, sino sobre la palabra "informe" que es la que aparece en primer lugar, y por tanto la que adquiere protagonismo. Esta precisión que atañe a la redacción es crucial tanto para el Periodismo como para la Historia. Si el Periodismo es el "borrador" de la Historia, como acertadamente afirma el profesor y periodista Vicente Clavero, la humildad de su condición no le puede eximir de la obligación de ser un borrador fiable. Por mucho que ambas disciplinas no sean las mismas, que evidentemente no lo son, no podemos obviar que hay mecanismos de verificación y contraste de fuentes que pueden ser útiles para ambas.

Algo que tampoco debemos olvidar es que esos mecanismos adquieren en los medios digitales una vía idónea para ser puestos en práctica. En los subtítulos que nos acompañan vamos a encontrar las pistas que nos indiquen por dónde podemos abordar la labor de verificación. En el primero se dice que " 11.000 presos han muerto en la cárcel...", lo cual tiene, sin duda, importancia para el historiador. Ahora bien, ese dato, sin lo que sigue -“... según un informe publicado por The Guardian y CNN"no tendría valor alguno desde el punto de vista de la fiabilidad. Pero por muy prestigiosos que sean los medios que avalan el dato, no dejan de ser en este caso fuentes terciarias, y no podemos dar por bueno lo que publica un diario simplemente citando otros medios. Hace falta algo más. Y ese algo más aparece en el segundo subtítulo: "Tres fiscales internacionales han elaborado el documento con pruebas obtenidas por desertores". Aquí ya llegamos hasta las fuentes secundarias (los fiscales ${ }^{1}$ y las primarias; estas últimas son las que han visto con sus propios ojos esas "torturas" y "asesinatos sistemáticos" de los que habla el titular principal.

Todavía, sin embargo, podemos obtener más garantías de fiabilidad (pasaremos por alto en el orden de lectura -sólo de momento- dos importantes hipervínculos y una veintena de asientos de documentación de los que el historiador, y el periodista, a buen seguro, van a poder sacar partido). Ya en el texto, en su primer párrafo, encontramos la identidad de uno de esos tres fiscales de los que hablaba el segundo subtítulo. 
Se trata de David Crane, que actuó en el proceso al presidente de Liberia Charles Taylor. Unas líneas más adelante el texto nos presenta al segundo fiscal, Geoffrey Nice, que se encargó de procesar al expresidente yugoslavo Slobodan Milosevic, y al tercero, Desmond de Silva, ex fiscal jefe del tribunal especial para Sierra Leona. La presencia de estos tres juristas, y sus destacadas hojas de servicio, van consolidando la fiabilidad que buscamos. Pero todavía no es total tampoco, claro. La veracidad de elpais.com todavía no se ha contrastado. Podría ser que tanto el dato de las 11.000 muertes -como el hecho de que están certificadas por tres prestigiosos juristas- fuera falso, o inexacto, o incompleto, o sacado de contexto, etc. A pesar de la credibilidad que le demos al medio, siempre se puede seguir afianzando el aval mediante el contraste con otros medios; sean españoles de esas mismas fechas, o extranjeros. Recordemos que las fuentes terciarias que nos ofrece el primer subtítulo son The Guardian y CNN. También podemos remontar más y acudir a las secundarias, entrevistar a los tres fiscales. Esto nos daría ya una seguridad jurídica. No pretendemos decir que esta tenga más valor que la historiográfica o la periodística - cualquier disciplina que ponga su principal valor en la veracidad de los hechos no puede admitir gradaciones en categorías que no la tienen-, pero sí que quienes avalan esa seguridad se encuentran en un punto más próximo a los hechos que los medios citados.

Todavía podemos remontar más en el proceso informativo y acudir ya, directamente, a las fuentes primarias. De momento sólo sabemos que se trata de "desertores", según quedó claro en el segundo subtítulo. En el texto nos enteramos de que la mayor parte de la información procede de un policía militar sirio apodado César. Su nombre verdadero, obviamente, no aparece. Si encontráramos a ese tal César - tarea harto difícil, por supuesto, tanto para un historiador como para un periodista- podríamos entrevistarle y obtener una verificación de grado uno, la máxima posible. Aquí es necesario entrar ya en el ámbito de una seguridad no total sino aceptable. Pero todavía podemos, porque así nos lo ofrece el diario, utilizar otros mecanismos de control que hemos ido dejando de lado en nuestro afán por establecer lo más claramente posible el curso del proceso. En primer lugar tenemos la autoría. El relato viene firmado por A. Carbajosa y T. Gualtieri, y la única datación que acompaña a estas firmas es la de "Madrid". Puede que estos nombres nos digan algo, o puede que no. En cualquier caso la firma nos ofrece la garantía de que esos dos redactores responden con ella de la veracidad de los datos expuestos, por lo menos en la misma medida que el medio. La datación nos informa de que esos dos periodistas no estaban en Siria viendo los hechos, sino en la redacción central. Tampoco este dato desvirtúa en nada la credibilidad del periódico ni la de los firmantes; muy al contrario, la apuntala desde el momento en que nos confirma una información que ya sabíamos, o por lo menos podíamos deducir a través del viaje que hemos hecho por el proceso informativo. Si los redactores hubieran visto con sus propios ojos los horrores de la guerra, sobrarían todas las demás fuentes. Por eso la ratificación de su lejanía con respecto a los hechos no supone una merma de credibilidad; sino que, desde el momento en que nos ofrecen su verdadera ubicación, sin tapujos, aportan confianza al lector. 
En segundo lugar, en el texto nos enteramos también de que las fuentes terciarias The Guardian y $C N N-$, o las secundarias -los fiscales- (elpais.com no lo especifica), han puesto en práctica un sistema propio de verificación. Quizá aquí convenga aclarar que, si bien el número de fuentes sucesivas puede ser inversamente proporcional a la credibilidad, el hecho de que todas ellas sean fiables convierte ese número en aval por sí mismo de ese crédito, puesto que esas fuentes han empleado, cada una por su cuenta, distintos sistemas de verificación que podemos considerar como correctos. La información, por tanto, lejos de desvirtuarse y perder nitidez en su paso por los distintos eslabones de la cadena, gana en credibilidad puesto que ha tenido que pasar muchos filtros antes de llegar a su destinatario final. En el caso que nos ocupa, el diario inglés y la cadena norteamericana o los juristas contaron con un experto británico en imágenes digitales que certificó la autenticidad de parte de las fotografías. Este dato lo cuenta el propio relato (que es nuestro único objeto de análisis), lo que sirve para corroborar que un texto periodístico bien construido no sólo debe dar cuenta de los hechos, sino también de los mecanismos de control que ha puesto en práctica cada uno de los agentes que intervienen en la transmisión de la información.

Queda más por hacer, sin embargo. Hasta ahora hemos descrito los distintos pasos que se pueden dar en aras de una verificación que pueda ser útil tanto al periodista como al historiador. En caso de verificación positiva, habremos demostrado que el cauce del río está limpio y que el agua baja transparente desde sus fuentes, pero todavía no que ese cauce no ha sido reconducido o canalizado artificial e interesadamente. Nuestro informe fue encargado a los fiscales por el gobierno de Catar, "que apoya la rebelión en contra del régimen de El Asad", se nos dice expresamente en el texto. Para evitar sospechas, dos de los fiscales se refieren a este hecho alegando que trabajaron de manera independiente y que el gobierno de Catar sólo les pidió autentificar el material. En principio no hay motivo alguno para desconfiar de estas palabras. Volvemos a invocar, para dar crédito a sus palabras, el currículum de los juristas, y además añadimos que el informe fue entregado y aceptado por instituciones como la ONU y diversos gobiernos y organizaciones de derechos humanos que el relato no especifica. Pero, con todo, no es en este caso esa invocación lo fundamental, sino la verificación de los juristas en sí. Naturalmente que el gobierno de Catar es parte interesada, pero ello no debe menoscabar en nada la credibilidad del informe, si creemos en la independencia de los fiscales. Si no admitiéramos en Periodismo, o en Historia, la información de una fuente, por sospechar de su falta de imparcialidad, ningún hecho saldría a la luz en cuanto revistiera cierto atisbo de conflicto.

Pensemos en el Watergate. ¿Va a ser menos creíble la labor de Woodward y Bernstein por el hecho de que fueron ayudados por un "garganta profunda" disidente del Partido Republicano? Ciertamente, no. La labor de los periodistas no es inmiscuirse en las motivaciones de la fuente, sino comprobar la autenticidad de su información. En nuestro caso, además, Catar no es fuente, sino solo financiador -propiciador, digamos-, por eso importan todavía menos sus intereses. Sólo es relevante que su dinero ha permitido a la verdad llegar a buen puerto. Ya se habrán preocupado los fiscales de no resultar intoxicados por posibles acciones que pudieran enturbiar la 
verificación. La fuente primaria - César en nuestro caso- también es parte interesada desde el momento en que también él es un disidente, en su caso del régimen sirio. Pero decimos lo mismo, eso en nada empaña, en principio, la validez de la información que suministra. Por poner ejemplos más recientes -también con marchamo de trascendencia histórica-, no podemos negar validez a los cientos de miles de noticias filtradas por Snowden o Assange porque en ambos episodios los filtradores hayan sido acusados de un ánimo antinorteamericano. Aunque ese ánimo fuera cierto, ello no resta ni un ápice de credibilidad a lo filtrado. ¿Se imagina alguien que si la información filtrada - en el caso de Wikileaks, también a The Guardian y El País, por cierto- fuera falsa, iban a protestar los protagonistas de las filtraciones, es decir, los gobernantes de medio mundo? ¿O puede ser falsa una información que ha acarreado ya a las fuentes, o difusores, peticiones de extradición (Snowden y Assange) y penas de cadena perpetua (soldado Manning)? Sinceramente, no lo creemos.

Decíamos antes que un relato periodístico bien construido debe reflejar no solo los hechos, sino también los procesos de verificación que avalan la veracidad de esos hechos. Para el historiador y para el periodista ambos son igual de importantes. Pues bien, en nuestro texto, de una extensión de una página (con la dificultad que supone hablar de páginas en un diario digital), sin contar con los titulares y con los vínculos a los que enseguida nos referiremos, aproximadamente dos tercios de la misma están dedicados a explicar el proceso de fiscalización. Los hechos en sí, muy crudos -insistimos-, y la contextualización política -importante también para el historiador, obviamente- apenas ocupan un tercio de la citada página. En esa labor de contextualización política no sobra nada que no pueda ser aprovechado como fuente historiográfica, debidamente contrastada también, como es lógico. Se hace referencia en el texto, por ejemplo, a que en la misma semana en que se publica el informe se van a reunir en Suiza representantes diplomáticos de los dos bandos de la contienda para buscar una salida pacífica a la guerra. Se dice también que en los tres años de conflicto armado han sido muchas las acusaciones de torturas y de crímenes contra los derechos humanos contra el régimen sirio. No se especifican esas acusaciones, pero para eso ya están los vínculos, de los que antes ya hemos dicho que dejábamos pasar pero "solo" de momento.

Con todo, como decíamos, la parte del león del texto la compone la dedicada a la verificación, y ello porque el informe constituye "la prueba documental más completa aportada hasta la fecha" de las atrocidades sirias. Sólo en número, las fotografías que contiene esta prueba documental son 24.000. Pero leamos un párrafo para comprender que la importancia del texto no reside solo en explicar la parte cuantitativa del documento, sino también en dar cuenta del proceso por el que se obtuvieron las imágenes. Creemos que es realmente representativo del escrúpulo con el que se ha tratado la labor de verificación en un texto que resulta modélico a este respecto:

César, que trabajó 13 años para la policía militar, desertó a un tercer país y se entrevistó el pasado enero con los investigadores. Les detalló el elaborado procedimiento burocrático que ejecuta el Ejército cada vez que muere un detenido. César era el encargado de fotografiar los cuerpos. Por un lado, porque eso les permitía a 
los militares emitir un certificado de defunción sin que las familias accedan a los cuerpos. Y por otro, fotografiaban, porque las imágenes confirmaban que las órdenes de ejecuciones se habían cumplido. Tras morir en el centro de detención, los cuerpos eran trasladados a un hospital militar. Allí, César, junto a un doctor y a un jurista, comenzaba su trabajo. El informante indicó que hubo días en los que fotografió hasta 50 cadáveres. Las causas oficiales de la muerte eran normalmente "ataques cardíacos" o "problemas respiratorios". La gran mayoría de los cuerpos son de hombres jóvenes y aparecen desnutridos.

Vista la extensión dedicada a la contrastación en el cuerpo de texto, quizá haya llegado ya el momento de abordar esos elementos del reportaje que habíamos apartado y que son propios y exclusivos del periodismo digital. Nos referimos a los dos hipervínculos y a la veintena de asientos documentales. El primer vínculo nos ofrece el informe completo en inglés obtenido por The Guardian. El segundo, una fotogalería con las torturas y ejecuciones en Siria. Sobra decir lo que ambos documentos tienen de utilidad para el historiador, una vez comprobada la veracidad de ambos. En las fotografías se aprecian "cuellos marcados por algún tipo de soga que indican muerte por estrangulamiento y torsos con heridas que los investigadores atribuyen a torturas y palizas". Las referencias documentales en las que se ha archivado el texto son exactamente veinte y las podemos citar todas para dar idea de la amplitud de contextos en los que se puede enmarcar nuestro texto, lo que a su vez le sirve al historiador para elegir el punto, o los puntos, de vista sobre los que quiere construir su relato historiográfico:

Bachar el Asad, The Guardian, Guerra Siria, Siria, Guerra civil, Tortura, Primavera árabe, Guerra, Integridad personal, Revoluciones, Oriente próximo, Prensa, Conflictos políticos, Asia, Conflictos, Delitos, Medios de comunicación, Comunicación, Política, Justicia.

Por supuesto, esta riqueza documental no sería posible sin los medios digitales. Tanto para la labor de profundización, como para la de buscar las perspectivas adecuadas -elementos imprescindibles en historiografía- esta riqueza resulta de valor incalculable. Además resulta más valiosa desde el momento en que ha quedado demostrado fehacientemente el rigor de la información. Y todo ello, por si fuera poco, con los medios digitales, de forma inmediata (Eiroa, 2014: 357-369).

\section{Twitter como herramienta de divulgación y metodología del estudio}

El análisis de la relación de Twitter con el mundo de la Historiografía ha confirmado la gran capacidad de esta red social para incorporar todas las actividades humanas e interrelacionar a los distintos individuos interesados en ellas. Cualquier manifestación cultural, deportiva, artística, científica, económica, política o social, es capaz de adaptar sus códigos comunicativos tradicionales a las nuevas formas de transmisión de los conocimientos representados por las redes sociales (Ramón, 2012: 127-140). 
Twitter puede transmitir información en un restringido espacio sobre cualquier actividad humana. Actúa como una "Red de Alerta Temprana" emitiendo una información importante que debe ser ampliada. Es lo que en el periodismo se conoce como flash informativo. Los estudios de campo muestran sobre todo un doble uso de Twitter: anuncio de la publicación de artículos y efemérides históricas.

Las fuentes informativas y científicas han comprendido que Twitter es de gran utilidad para enviar sus mensajes (consideramos como "fuentes" tanto las instituciones como los individuos). Los ciudadanos acceden directamente a la divulgación de conocimientos y de opiniones sin utilizar los medios de comunicación convencionales. Las redes sociales son el nuevo puente entre la sociedad y las instituciones que actúan como fuentes (Pérez: 2014).

El estudio ofrece una visión del uso de Twitter que están haciendo agentes relacionados con la Historiografía de España, Europa y América. No se trata de un examen exhaustivo, sino más bien de una "fotografía" en un momento concreto (segundo trimestre de 2014). Posiblemente los datos quedarán desfasados dentro de un tiempo, pero servirán para futuros trabajos.

El método empleado ha sido la observación de la red Twitter para censar las cuentas oficiales de organismos académicos, historiadores y estudiantes de Historia, pero también las cuentas de publicaciones y las de aficionados a esta ciencia. Se incluyen 138 cuentas de Twitter relacionadas con la Historiografía que suman 2.988.198 seguidores y una actividad total de 764.082 tuits. No todos ellos contienen información histórica, porque algunos de los titulares de cuentas también las usan para expresarse sobre otras cuestiones.

En principio puede parecer espectacular el número de 2.988.198 seguidores para sólo 138 cuentas, pero conviene contextualizarlo: 2.456.000, corresponden sólo a tres cuentas de fotografía histórica: @HistoricalPics (1.300.000), @AbandonedPics (641.000) y @HistoryInPix (515.000). Los otros 532.198 seguidores se reparten entre las 135 cuentas restantes. Las que tienen un mayor número de seguidores (aunque no con mayor actividad "tuitera") son anglosajonas, debido sin duda al carácter global del idioma inglés. Las cuentas en español tienen muchos menos seguidores, independientemente de quien sea su titular o del tema que traten. El mayor número de seguidores no se corresponde con las cuentas con mayor número de tuits. Podríamos deducir que los seguidores no se sienten atraídos por la cantidad de tuits, sino por el prestigio de quien los emite, la calidad o el tema que contienen.

Se han elaborado nueve cuadros estadísticos con las cifras de tuits y de seguidores, tratando de establecer una categorización de las cuentas por sus titulares y por su grado de especialización, sorprendente en algunos casos como veremos. 
5.1. Las cuentas de Twitter en el campo de la Historia

Las categorías en las cuentas de Twitter analizadas han observado los siguientes criterios:

- Titular de la cuenta:

- Universidades, organismos académicos, museos y foros de Historia

- Historiadores profesionales y personas interesadas en la Historia

- Blogs, portales, webs, publicaciones

- Tema:

- Especializadas en una época histórica

- Especializadas en temas concretos

- Guerras

- Fotografía

- Carácter:

- Divulgativas

- "Fakes" de personajes históricos

En ocasiones resulta complicado asignar una cuenta a una categoría u otra por su transversalidad. Para evitar confusiones y duplicidades se ha renunciado a incluirlas en dos a la vez.

Cuentas de Universidades, museos y foros de Historia (Cuadro 1)

Este primer cuadro engloba la actividad en Twitter de instituciones académicas que divulgan trabajos de investigación (@catedranaval) o sus actividades culturales (@ Alcazar_Segovia). Asimismo, se han incluido cuentas de instituciones para el estudio del Latín@CCHSLatin (anglosajona).

Cuentas individuales de historiadores y personas interesadas en el conocimiento histórico (Cuadro 2)

Incluye a los historiadores que trabajan con metodología científica y a los que podríamos considerar "aficionados" (sin ánimo peyorativo).

Esas personas interesadas incluirían a los que aprenden Historia sin una regulación académica (lectura de libros, visionado de documentales, etc.) y a los licenciados que no se dedican a la investigación científica. Encontramos cuentas individuales de historiadores profesionales que anuncian sus últimos trabajos o expresan opiniones científicas. Y esos "aficionados" que transmiten sus emociones sobre hechos históricos o rememoran efemérides. 
Se han localizado 33 cuentas de Twitter con 43.732 seguidores y 252.600 tuits:

- Historiadores profesionales: 19 cuentas, 31.421 seguidores y 56.771 tuits.

- Personas interesadas en la Historia: 14 cuentas, 12.311 seguidores y 195.829 tuits (esta última cifra recoge también tuits no relacionados con la Historia).

\section{Cuentas de Blogs, portales y publicaciones (Cuadro 3)}

Este apartado resulta muy variado. Sin duda, se trata de utilizar la Red Social Twitter como escaparate para atraer visitantes a esas páginas.

Hay portales colectivos como (@hch_mexico),blogs individuales (@CorresponsalHis), publicaciones (@FrontHistoria) o los de "ayuda para estudiantes de Historia"(@Lhistorica).

\section{Cuentas especializadas en una época concreta (Cuadro 4)}

Las épocas con mayor presencia de cuentas de Twitter son Roma, (@LaRomapedia), la Prehistoria y la Historia Antigua en general (@Edad_Antigua). También hay muchas dedicadas a la Arqueología (@FATAPUERCA) y hay cuentas que además recogen temas profesionales (@AMTTArq).

\section{Cuentas especializadas en un tema histórico concreto (Cuadro 5)}

Comprende dos subcategorías: Temas Concretos y las de Alta Especialización. Entre las primeras figuraría @BatallasdGuerra. Entre las "altamente especializadas" destacamos @tsushima_1905 (Guerra Ruso-Japonesa).

Consideramos una cuenta "especializada" o "altamente especializada" según su contexto geográfico y la difusión de cada tema. Por ejemplo, la Guerra Ruso-Japonesa de 1905, que en España no es demasiado conocida.

\section{Cuentas sobre la Guerra Civil, guerras mundiales y Siglo XX (Cuadro 6)}

Este apartado ha representado una cierta sorpresa porque han aparecido pocas cuentas, a pesar de que la Guerra Civil española y la II Guerra Mundial acaparan la atención permanente de los informativos y del público. Ni siquiera los aniversarios de 2014 (I Guerra Mundial y Normandía) animaron suficientemente a los tuiteros. Se incluyen cuentas sobre el siglo XX que mencionan las guerras que lo asolaron (@) UnSigloEnGuerra).

\section{Cuentas divulgativas (Cuadro 7)}

En este apartado agrupamos las cuentas que explican la Historia con sentido divulgativo, algunas con anécdotas y otras con afán de amenidad. 


\section{Cuentas de "Fakes" con personajes históricos (Cuadro 8)}

Cuentas "firmadas" por personajes históricos. Utilizamos el anglicismo fake como sinónimo de "cuenta falsa" que suplanta a famosos. Fake es un término habitual en Twitter, aunque posiblemente aquí no sea adecuado, porque los fakes caricaturizan al personaje suplantado. Por el contrario, estas cuentas expresan admiración por los personajes históricos.

Cuentas de fotografía y recorridos culturales (Cuadro 9)

En el cuadro 9 aparecen los tres gigantes mencionados. Son galerías fotográficas en inglés con casi dos millones y medio de seguidores y otras españolas. Quizá alguna no debería considerarse propiamente una cuenta de Historia, pero toda fotografía antigua tiene un carácter histórico.

\section{Anexo estadístico}

Cuadro 1. Universidades, Museos y Foros de Historia

\begin{tabular}{|c|c|c|}
\hline CUENTA & SEGUIDORES & TUITS \\
\hline @)EmanuelClassics & 257 & 70 \\
\hline @CCHSLatin & 353 & 338 \\
\hline @)teach_classics & 433 & 237 \\
\hline (a)QueensClassics & 589 & 437 \\
\hline @catedranaval & 718 & 3.518 \\
\hline @hinmediata & 1.988 & 1.527 \\
\hline @historiadebate & 2.586 & 1.355 \\
\hline @ historiaabierta & 2.244 & 582 \\
\hline @memoriademadrid & 627 & 197 \\
\hline @LaPicaenFlandes & 117 & 221 \\
\hline @felalinde & 162 & 1.530 \\
\hline @Alcazar_Segovia & 375 & 380 \\
\hline @Museo_Naval & 5.035 & 8.908 \\
\hline @ MuseosNavales & 602 & 659 \\
\hline @IhyCM_ET & 819 & 42 \\
\hline
\end{tabular}

Fuente: Elaboración propia

Cuadro 2. Historiadores profesionales y aficionados

\begin{tabular}{|l|c|c|}
\hline \multicolumn{1}{|c|}{ CUENTA } & SEGUIDORES & TUITS \\
\hline @angelvinashist & 86 & 62 \\
\hline$@$ alf_avi & 1.580 & 9.610 \\
\hline @Andreag1086 & 118 & 3.008 \\
\hline @ kershaw_alex & 661 & 954 \\
\hline
\end{tabular}




\begin{tabular}{|c|c|c|}
\hline CUENTA & SEGUIDORES & TUITS \\
\hline @,AbigailPfeiffer & 945 & 1.609 \\
\hline @,isapovea & 1.112 & 13.100 \\
\hline (a)cbarrosg & 648 & 3.067 \\
\hline (a)Vaktelforlag & 746 & 378 \\
\hline (a)cliocaribe & 254 & 611 \\
\hline @fpecastro & 112 & 443 \\
\hline @victorarrambide & 565 & 12.000 \\
\hline (a)Barber1944 & 1.583 & 1.080 \\
\hline @Victor_Gayol & 243 & 360 \\
\hline @Eder_Gallegos & 177 & 3.391 \\
\hline$@$ MaritxuJones & 159 & 501 \\
\hline$@$ PerezPuenteL & 118 & 160 \\
\hline$@$ StevenDMercatan & 351 & 249 \\
\hline$@$ nelsonmanrique & 21.800 & 5.020 \\
\hline @JAriza10 & 163 & 1.168 \\
\hline \multicolumn{3}{|c|}{ “AFICIONADOS” A LA HISTORIA } \\
\hline @HugoIpina06 & 172 & 10.300 \\
\hline @RosanaGobello & 220 & 6.458 \\
\hline @)silviabroome & 1.994 & 65.300 \\
\hline (a)_porcel & 887 & 37.500 \\
\hline (a)gvillrod & 40 & 863 \\
\hline (a)marksimner & 1.665 & 10.900 \\
\hline @PaulMorley72 & 215 & 434 \\
\hline @)Alvaro_Loro & 1.457 & 2.190 \\
\hline @jvegavara & 3.237 & 41.500 \\
\hline (a) estherglezs & 279 & 7.599 \\
\hline @joseragas & 1.349 & 8.828 \\
\hline @ali_lovetzn & 139 & 1.602 \\
\hline @alrivas76 & 242 & 701 \\
\hline @inesgce & 415 & 1.654 \\
\hline
\end{tabular}

Fuente: Elaboración propia

Cuadro 3. Blogs y publicaciones

\begin{tabular}{|c|c|c|}
\hline CUENTA & SEGUIDORES & TUITS \\
\hline @ hhch_mexico & 1.121 & 591 \\
\hline @CorresponsalHis & 439 & 158 \\
\hline @ wikihistoria & 14.200 & 6.218 \\
\hline @ $a$ REX_GERMANUS & 2.912 & 6.641 \\
\hline @ canalpatrimonio. & 9.468 & 21.600 \\
\hline @prehistorialdia & 1.118 & 2.367 \\
\hline @)Paleoaprende & 624 & 978 \\
\hline @red_historia & 11.800 & 4.390 \\
\hline @TwitstoriadeEsp & 48.100 & 10.900 \\
\hline
\end{tabular}




\begin{tabular}{|l|c|c|}
\hline \multicolumn{1}{|c|}{ CUENTA } & SEGUIDORES & TUITS \\
\hline @SPQRHistoria & 1.403 & 44 \\
\hline @RetoHistorico & 5.831 & 19.500 \\
\hline @_antiguoscafes & 273 & 1.297 \\
\hline @HRMilitaris & 2.450 & 2.623 \\
\hline @Lhistorica & 4.638 & 5.908 \\
\hline @LBHobsbawm & 1.106 & 919 \\
\hline @Hyotrasdrogas & 2.636 & 788 \\
\hline Geacron @ggeacron & 1.719 & 8.508 \\
\hline @FrontHistoria & 513 & 310 \\
\hline @muyhistoria & 13.800 & 21.600 \\
\hline @Historiassegund & 1.573 & 1.347 \\
\hline @1asegundaguerra & 2.157 & 3.482 \\
\hline @ AprendeHistoria & 22.400 & 3.837 \\
\hline
\end{tabular}

Fuente: Elaboración propia

Cuadro 4. Cuentas especializadas en una época concreta

\begin{tabular}{|l|c|c|}
\hline \multicolumn{1}{|c|}{ CUENTA } & SEGUIDORES & TUITS \\
\hline @LaRomapedia & 6.389 & 5.885 \\
\hline @antigua_roma & 20.600 & 7.501 \\
\hline @Edad_Antigua & 4.124 & 1.627 \\
\hline @Anacronicos & 1.560 & 12.900 \\
\hline @historyancient & 10.900 & 2.981 \\
\hline @arqueo2bytes & 1.981 & 4.240 \\
\hline @ tothistoria & 954 & 2.374 \\
\hline @sotaterra & 1.632 & 1.487 \\
\hline @paleotwit & 8.118 & 15.300 \\
\hline @FATAPUERCA & 7.538 & 6.908 \\
\hline @Paleoaprende & 625 & 978 \\
\hline @,Antrophistoria & 21.600 & 12.100 \\
\hline @LaBdeJenri & 3.216 & 12.900 \\
\hline @Arqueolitic & 769 & 263 \\
\hline @arqueodidat & 2.198 & 3.047 \\
\hline @AMTTArq & 388 & 329 \\
\hline @arqueologia_ & 965 & 1.205 \\
\hline
\end{tabular}

Fuente: Elaboración propia

Cuadro 5. Cuentas especializadas en temas concretos

\begin{tabular}{|l|c|c|}
\hline \multicolumn{1}{|c|}{ CUENTA } & SEGUIDORES & TUITS \\
\hline @RomanicoEspana & 2.369 & 8.890 \\
\hline$@$ monarquia_esp & 27.400 & 2.013 \\
\hline @ BritMilHistory & 1350 & 457 \\
\hline @ BatallasdGuerra & 25.100 & 4.005 \\
\hline
\end{tabular}




\begin{tabular}{|l|c|c|}
\hline \multicolumn{1}{|c|}{ CUENTA } & SEGUIDORES & TUITS \\
\hline @tsushima_1905 & 226 & 1.112 \\
\hline @LasTresCulturas & 3.219 & 1.354 \\
\hline @RutasdeGuerra & 914 & 1.724 \\
\hline @elcaminoespanol & 1.768 & 4.483 \\
\hline @SubmarinosES & 462 & 284 \\
\hline @buquesarmada & 486 & 143 \\
\hline @arcabucero & 105 & 1.703 \\
\hline
\end{tabular}

Fuente: Elaboración propia

Cuadro 6. Guerra Civil, Guerras Mundiales, Siglo XX

\begin{tabular}{|l|c|c|}
\hline \multicolumn{1}{|c|}{ CUENTA } & SEGUIDORES & TUITS \\
\hline @guerraenmadrid & 1.556 & 1.584 \\
\hline @DefensaDeMadrid & 15.700 & 26.800 \\
\hline @Buscameblog & 14.200 & 6.005 \\
\hline @HistoriaIIGM. & 95 & 41 \\
\hline @livefromww & 3.990 & 1.594 \\
\hline @SASEGM & 1.846 & 1.513 \\
\hline @jigg1974 & 10.600 & 22.300 \\
\hline @chinaww2 & 2.897 & 1.903 \\
\hline @WarHistoryOL & 4.956 & 20.700 \\
\hline @UnSigloEnGuerra & 4.672 & 651 \\
\hline @historia_SXX & 9.020 & 5.425 \\
\hline @HistoriaMilita & 4.417 & 3.726 \\
\hline
\end{tabular}

Fuente: Elaboración propia

Cuadro 7. Divulgativas

\begin{tabular}{|l|c|c|}
\hline \multicolumn{1}{|c|}{ CUENTA } & SEGUIDORES & TUITS \\
\hline @oCesar_o Nada & 3.597 & 7.963 \\
\hline @,rodelayacero & 965 & 804 \\
\hline @ quhist. & 2.906 & 17.900 \\
\hline @ historia_twi & 4.089 & 2.743 \\
\hline @ mibrevehistoria & 5.017 & 1.589 \\
\hline @ tophistoria & 2.582 & 456 \\
\hline @LLa_otrahistoria & 4.070 & 7.372 \\
\hline
\end{tabular}

Fuente: Elaboración propia

Cuadro 8. Fakes de personajes históricos

\begin{tabular}{|l|c|c|}
\hline \multicolumn{1}{|c|}{ CUENTA } & SEGUIDORES & TUITS \\
\hline @ Otrashistorias & 1.490 & 1.337 \\
\hline @ FelipeIIAustria & 1.133 & 234 \\
\hline @ CarlosIdeEspana & 1.791 & 1.609 \\
\hline
\end{tabular}




\begin{tabular}{|l|c|c|}
\hline \multicolumn{1}{|c|}{ CUENTA } & SEGUIDORES & TUITS \\
\hline @Joan_Prim_Prats & 1.054 & 3.824 \\
\hline @Espinola_Ambros & 879 & 684 \\
\hline @Duque_de_Alba & 5.242 & 8.743 \\
\hline @DonJuanDAustria & 12.200 & 36.400 \\
\hline @A_Farnesio93 & 379 & 7.659 \\
\hline
\end{tabular}

Fuente: Elaboración propia

Cuadro 9. Galerías fotográficas y recorridos culturales

\begin{tabular}{|l|c|c|}
\hline \multicolumn{1}{|c|}{ CUENTA } & SEGUIDORES & TUITS \\
\hline @HistoricalPics & 1.300 .000 & 4.743 \\
\hline @ colour_history & 2.033 & 203 \\
\hline @HistoryInPix & 515.000 & 1.608 \\
\hline @,AbandonedPics & 641.000 & 599 \\
\hline @_ElRetiro & 5.522 & 2.502 \\
\hline @ paisajehistoria & 1.647 & 542 \\
\hline @DescubreMayrit & 3.776 & 7.789 \\
\hline @MadridenRuta & 2.605 & 7.325 \\
\hline @Ls_Madriles & 8.414 & 5.130 \\
\hline @CallejeandoMad & 11.400 & 2.771 \\
\hline @Pennypol & 2.288 & 5.189 \\
\hline @MayritMadrid & 279 & 4.442 \\
\hline @ImgenesH & 5.017 & 15.100 \\
\hline
\end{tabular}

Fuente: Elaboración propia

\section{Conclusiones}

1. La digitalización de los medios ha acrecentado la oferta informativa hasta el punto de convertirse en una masa de noticias difíciles de seguir y de catalogar por las audiencias. La sucesión de noticias han transformado el relato periodístico en una sucesión en forma de "película" con preeminencia de la continuidad y de la inmediatez. Otros efectos son la progresiva pérdida del papel de intermediarios de los mes, la interactuación con las audiencias y la cesión de la "agenda setting" a las redes sociales.

2. El Periodismo de Investigación (PI) se esfuerza en aportar por un lado el máximo rigor posible en la elaboración de las informaciones y por otro en rehuir en lo posible la inmediatez.

3. E1 PI desarrollado alrededor de grandes cantidades de datos procesados aporta una nueva visión informativa, más basada en los procesos que en las causas. 
4. El estudio de la Historia ha encontrado en Twitter un importante canal para divulgar los conocimientos tradicionales y los descubrimientos más recientes.

5. Universidades, historiadores y aficionados han inundado esta red social con sus cuentas para interrelacionarse.

6. Las fuentes científicas han comprendido la utilidad de Twitter y su función para divulgar sus investigaciones.

7. Las redes sociales representan el nuevo puente entre la sociedad y las instituciones que actúan como fuentes del conocimiento. Los ciudadanos pueden acceder directamente sin utilizar los medios de comunicación convencionales.

8. Las cuentas en inglés llegan a acumular millones de seguidores, cifras muy superiores a las cuentas en español.

\section{Referencias bibliográficas}

CASASÚS, J. M. (2005). "Nuevos conceptos teóricos para la investigación en Periodismo Digital". En: Actas del VII Congreso de la Sociedad Española de Periodística "Las tecnologías periodísticas: del ayer al mañana". Sevilla, SEP.

CASERO, A. (2014). "La pérdida de valor de la información periodística: causas y consecuencias". En: Anuario ThinkEPI, 8.

DÍAZ, L. (2003). Periodismo y periodistas de investigación en España, 1975-2000: contribución al cambio político, jurídico, económico y social. Tesis Doctoral, Universidad Complutense de Madrid.

EIROA, M. (2002). "Consideraciones sobre las fuentes mediáticas (o los media no pueden construir la Historia)". En: Actas del III Simposio de Historia Actual, Logroño: Instituto de Estudios Riojanos.

EIROA, M. (2014). "Historia y periodismo: interrelaciones entre disciplinas". En: Historia y Comunicación Social, $\mathrm{n}^{\circ}$ 19, número especial.

EIROA, M. (2014). "La Guerra Civil española en la actualidad cibermediática". En: Studia Historica $H^{a}$ Cont., $\mathrm{n}^{\circ} 32$.

HAN, B. (2013). La sociedad de la transparencia. Barcelona: Herder.

PÉREZ, G. (2014). "Twitteando el centenario de la Gran Guerra: ¿hacia un espacio virtual de la memoria". En: Actas del XII Congreso de Historia Contemporánea. Pensar en la Historia desde el Siglo XXI. Madrid.

ROMERO, L. (2005). "La aplicación de las bases de datos al Periodismo". En: Actas del VII Congreso de la Sociedad Española de Periodística "Las tecnologías periodísticas: del ayer al mañana", Sevilla: Sociedad Española de Periodística.

SANMARTÍ, J. M.; PANIAGUA. P.; RAMÓN, M. (2002). "Periodismo, la plebeyización triunfante. Los medios como indicadores de la Historia". En: Actas del III Simposio de Historia Actual, Logroño: Instituto de Estudios Riojanos.

YUNQUERA, J. (2014). Desarrollo de las publicaciones digitales y nuevos soportes informativos. Tesis Doctoral, Universidad Carlos III de Madrid. 
Webs

ALVES, R. (2010). En: ELOLA, J. "Los medios deben aparcar su arrogancia”. elpais. com, 5 de septiembre.

ARMADA, A. (2014). "El prestigio de una publicación, sea digital o en papel, está basado en el rigor". En: XV Congreso Periodismo Digital de Huesca http://www. congresoperiodismo.com/noticias_detalle.asp?idNoticia $=41 \&$ portada $=1 \quad[24 \mathrm{de}$ septiembre 2014].

CEBRIÁN, J. L. (2011). "Wikiperiodismo". elpais.com, 24 de febrero.

ELOLA, J. (2010). "Los medios deben aparcar su arrogancia". En: elpais.com, 5 de septiembre http://elpais.com/diario/2010/09/05/domingo/1283658757_850215. html [15 de noviembre 2014).

FILTRALA.ORG (2014). En: https://data.awp.is/filtrala/2014/06/13/4.htm.

GUTIÉRREZ, O. (2011): “Moreno: “En unos años, pocos o muchos, dejará de haber periódicos de papel"”. En: elpais.com, 11 de marzo.

HERNÁNDEZ, Esteban (2013). “'Big data': ¿el nuevo poder absoluto que controlará nuestras vidas?". En: elconfidencial.com, 25 de noviembre.

MAGALLÓN, R. (2013). "Nuevos modelos periodísticos: formas de financiación y tendencias para 2013". En: blog de 16 de enero, http://www.www.bottup. com/201301168957/Medios/nuevos-modelos-periodisticos-formas-de-financiacion-y-tendencias-para-2013.html\#ixzz2JIUkrzWb [2 septiembre 2014].

RAMÓN, M. de (2012). "Un nuevo lenguaje para los medios periodísticos digitales". En: Revista de Comunicación de la SEECI, año XV (32), noviembre http://www. seeci.net/revista/index.php/seeci/article/view/25

\section{Notas}

1 En un párrafo completo del texto que reproducimos más adelante se habla de que un jurista acompañaba al desertor en el momento de fotografiar los cuerpos de la matanza del régimen sirio. En el caso de que ese jurista fuera uno de los fiscales que firman el informe (el diario no lo especifica), ese fiscal sería fuente primaria y no secundaria. 